\title{
Effect of build location on microstructural characteristics and corrosion behavior of EB-PBF built Alloy 718
}

\author{
P. Karimi ${ }^{1}$ - E. Sadeghi ${ }^{1}$ • J. Ålgårdh ${ }^{1,2} \cdot$ P. Harlin ${ }^{3} \cdot$ J. Andersson ${ }^{1}$
}

Received: 22 August 2019 / Accepted: 18 December 2019/Published online: 6 January 2020

(C) The Author(s) 2020

\begin{abstract}
Electron beam-powder bed fusion (EB-PBF), a high-temperature additive manufacturing (AM) technique, shows great promise in the production of high-quality metallic parts in different applications such as the aerospace industry. To achieve a higher build efficiency, it is ideal to build multiple parts together with as low spacing as possible between the respective parts. In the EB-PBF technique, there are many unknown variations in microstructural characteristics and functional performance that could be induced as a result of the location of the parts on the build plate, gaps between the parts and part geometry, etc. In the present study, the variations in the microstructure and corrosion performance as a function of the parts location on the build plate in the EB-PBF process were investigated. The microstructural features were correlated with the thermal history of the samples built in different locations on the build plate, including exterior (the outermost), middle (between the outermost and innermost), and interior (the innermost) regions. The cubic coupons located in the exterior regions showed increased level ( $20 \%)$ of defects (mainly in the form of shrinkage pores) and lower level $(\sim 30-35 \%)$ of $\mathrm{Nb}$-rich phase fraction due to their higher cooling rates compared to the interior and middle samples. Electrochemical investigations showed that the location indirectly had a substantial influence on the corrosion behavior, verified by a significant increase in polarization resistance $\left(R_{\mathrm{p}}\right)$ from the exterior $\left(2.1 \pm 0.3 \mathrm{k} \Omega . \mathrm{cm}^{2}\right)$ to interior regions $\left(39.2 \pm 4.1 \mathrm{k} \Omega . \mathrm{cm}^{2}\right)$.
\end{abstract}

Keywords Additive manufacturing $\cdot$ Electron beam-powder bed fusion $\cdot$ Alloy $718 \cdot$ Hardness $\cdot$ Microstructural characterization $\cdot$ Corrosion

\section{Introduction}

Additive manufacturing (AM) processes can build parts using computer-aided design (CAD) drawing through stacking layers on top of the others $[1,2]$. There is a growing number of metal AM techniques which are able to manufacture geometrically complex parts [3]. Over the last decade, the maturity of these techniques has been largely increased due to numerous research performed providing a deeper understanding of the material-process-microstructure-properties relationship [4]. It has been recognized that AM of metallic parts

P. Karimi

paria.karimi@hv.se

1 Department of Engineering Science, University West, 461 86 Trollhättan, Sweden

2 GE Additive | Arcam EBM, Designvägen 2, 435 33 Mölnlycke, Sweden

3 Sandvik Additive Manufacturing, 81181 Sandviken, Sweden offers much promise for the production of highly engineered or complex parts, but the relatively low technology readiness of AM implies that there are many aspects of AM unknown [5]-[8].

Electron beam-powder bed fusion (EB-PBF) technique is a high-temperature $\mathrm{AM}$ process running in a relatively high vacuum chamber used to build high-temperature metallic parts [1]. The EB-PBF as AM process is of interest due to its several advantages over conventional manufacturing processes, such as freedom to build intricate geometries, optimum material usage, elimination of expensive tooling, etc. [9]. Apart from the machine-related parameters such as scanning speed, beam current, focus offset, line offset, etc., the positionrelated parameters which are linked to the type of stacking or orientations of the parts on the build plate must be carefully monitored [10]. These parameters consist of (a) distance between the parts on the build plate, (b) height of the part from the build plate, (c) location of the parts on the build plate, and (d) angle of the parts on the build plate [10]-[12]. Microstructure and resulting properties of the EB-PBF manufactured parts have been observed to be affected by some 
of these position-related parameters $[6,10,11,13]$. Although each of the position-related parameters can have a significant effect on the thermal history of an EB-PBF built part, there is a lack of knowledge in the literature on the effect of these parameters on the microstructure and functional performance of the manufactured parts $[11,14,15]$.

In the present work, Alloy 718 is the material of interest owing to its extensive applications in the aerospace industry and the availability of well-established process themes for the alloy in the EB-PBF machines [8, 10, 16, 17]. In this paper, the manufacturing constraints of the EB-PBF built Alloy 718 are investigated to issue recommendations to the designers. In a previous study [10], it was found that the gap between the samples and height from the build plate affect the microstructural characteristics such as $\mathrm{Nb}$-rich phase fraction and level of defects. However, the influence of the sample location due to a limited number of manufactured samples on the build plate did not show a clear trend [18]. Similar to the effects of the gap between the samples and the height from the build plate on the microstructure, it is assumed that the part location shows similar behavior on the microstructure. As shown in Fig. 1, there is a hypothesis that the innermost region (defined as "interior region") of the build space is warmer, and the temperature radially decreases towards the outermost region (defined as "exterior region") [10, 11]. It can, therefore, be expected that parts built in the exterior region have a finer microstructure and higher hardness compared to the parts built in the interior region.

Alloy 718 has been originally developed for use in elevated temperature applications; however, the alloy has also shown excellent room temperature properties like low-temperature corrosion protection [19]. Corrosion performance is known as an important aspect of advanced materials in real applications [7, 20, 21]. In general, to depict a high corrosion resistance, the materials need to be dense or defect-free, rich in passive (or protective)layer forming elements such as $\mathrm{Cr}$, and have an appropriate grain size in a given corrosive environment [22]. The presence of pores is detrimental for corrosion performance as corrosive species like oxygen $\left(\mathrm{O}^{2-}\right)$ or chloride $\left(\mathrm{Cl}^{-}\right)$can easily penetrate into the bulk material. Formation of $\mathrm{Cr}$-containing phases like $\mathrm{Cr}$-rich carbides decreases the $\mathrm{Cr}$ reservoir required for formation of the passive layer (i.e., a protective chromia layer in Alloy 718). The effect of the grain size is still unknown, but it has been shown that the severity of the corrosive environment defines whether a fine or coarse microstructure is more appropriate [23]. When the environment is highly corrosive containing the aggressive $\mathrm{Cl}^{-}$ions, the fine grains are improper as inward diffusion of tiny $\mathrm{Cl}^{-}$outweighs the outward diffusion of the passive layer-forming elements (like $\mathrm{Cr}$ in Alloy 718) through the grain boundaries. However, the exact effect of the grain size on the corrosion performance needs to be studied in a given environment. The location of the parts built in different locations on the build plate can have a strong influence on the level of pores, phases, and grains structure, as the thermal history of the parts varies depending on the level of heat accumulation in each part.

So, the aim of the present study is to investigate the location dependency of material properties built by the EB-PBF process where several parts are simultaneously built on the build plate in one batch. The work presented here specifically intends to address the effects of the parts location on the microstructural characteristics of Alloy 718 manufactured in the EB-PBF process. Moreover, electrochemical tests were also performed to analyze the effect of the sample's location on the corrosion performance. In fact, to the best of the authors' knowledge and apart from the results of the preliminary study [10], no related study has been published to correlate the microstructure and properties of the parts manufactured using the EB-PBF process for Alloy 718 to the location of the parts [10]. Hence, the focus in the present study is to bridge this research gap to better understand the relationship between the parts' location to the microstructure and corrosion performance of the parts manufactured by the EB-PBF process.

\section{Materials and experimental work}

\subsection{Feedstock powder}

Gas-atomized Alloy 718 powder supplied by Sandvik AB (Sandviken, Sweden) was used as feedstock. The powder was a mixture of irregular and spherical-shaped particles with
Fig. 1 Simplified schematic of temperature distribution map on the parts, build plate, and powder bed

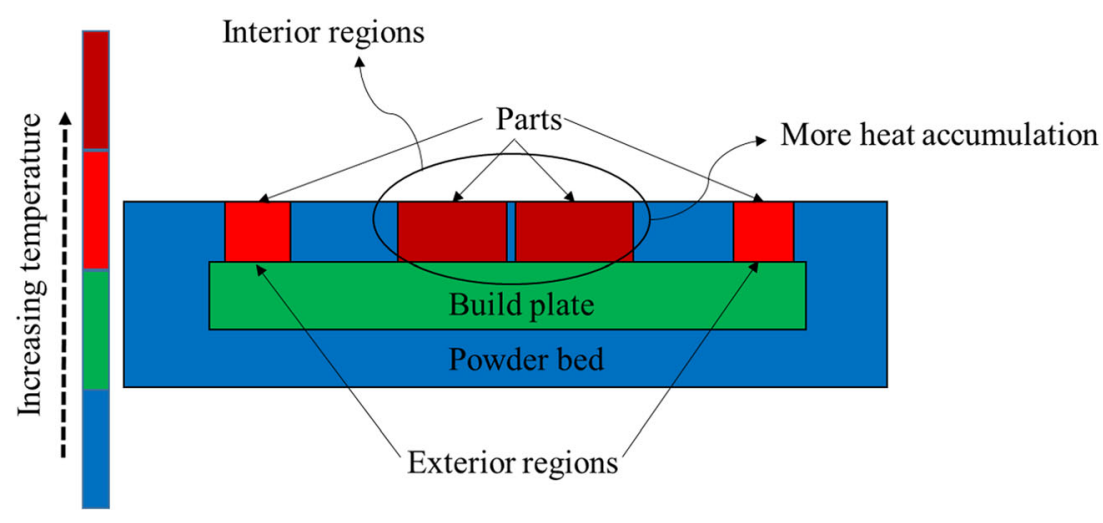


a few small satellites attached to the surface of coarser particles, see Fig. 2a. A few internal round pores formed during powder manufacturing can be seen in Fig. $2 \mathrm{~b}$. The particle size of the feedstock powder was $45-106 \mu \mathrm{m}$ reported from the supplier. The chemical composition in wt $\%$ of the powder is given in Table 1.

\subsection{Sample manufacturing}

The build process was conducted at University West (Sweden) an A2X machine manufactured by Arcam-EBM (a GE additive, Mölndal, Sweden) under a controlled vacuum of $2 \times 10^{-3} \mathrm{mbar}$ with a small amount of helium in the build chamber and an acceleration voltage of $60 \mathrm{kV}$. The build temperature was kept at $\sim 1015{ }^{\circ} \mathrm{C}$ measured by a thermocouple beneath the build plate throughout the process, see Fig. 3. Twelve cubic samples divided in four groups (A, B, C, and D) with different locations were manufactured, see Fig. 3. Each group consisted of three samples including exterior, middle, and interior parts. All the samples had the same dimension of $15 \mathrm{~mm} \times 15 \mathrm{~mm} \times 15 \mathrm{~mm}$ and were built with the process parameters shown in Table 3 (Arcam-EBM recommended theme for Alloy 718). A plate of stainless steel with the dimension of $10 \mathrm{~mm} \times 150 \mathrm{~mm} \times$ $150 \mathrm{~mm}$ was used as the build plate.

\subsection{Characterization of microstructure}

The samples were cut from a normal reference plane parallel to the build direction (Fig. 3b) using an alumina cutting blade, followed by grinding using 120-Grit $\mathrm{SiC}$ paper up to 4000 grit size and finally polishing with colloidal silica suspension $(0.05 \mu \mathrm{m})$. The samples were then etched electrolytically using oxalic acid $(10 \mathrm{wt} \%)$ at room temperature with $6 \mathrm{~V}$ for 5 to $10 \mathrm{~s}$. The microstructure of the samples was analyzed by a Zeiss light optical microscope (LOM) (Axio Scope.A1, NY, USA). For each sample, sixteen micrographs (with the field width of $500 \mu \mathrm{m}$ ) were taken to examine pores and lack-offusion defects based on the point counting method presented in ASTM 562-08 [24].

A Hitachi scanning electron microscope (SEM) (TM3000, Tokyo, Japan) was used to characterize the microstructures.
Table 1 Chemical composition of Alloy 718 powder (in wt $\%$ )

\begin{tabular}{cccccccc}
\hline Element & $\mathrm{Ni}$ & $\mathrm{Co}$ & $\mathrm{Cr}$ & $\mathrm{Mo}$ & $\mathrm{Ti}$ & $\mathrm{S}$ & $\mathrm{Si}$ \\
\hline wt\% & 53.3 & 0.01 & 18.7 & 3.0 & 0.94 & 0.001 & 0.05 \\
Element & $\mathrm{C}$ & $\mathrm{Mn}$ & $\mathrm{Nb}$ & $\mathrm{P}$ & $\mathrm{Al}$ & $\mathrm{B}$ & $\mathrm{Fe}$ \\
$\mathrm{wt} \%$ & 0.028 & 0.07 & 5.14 & 0.003 & 0.42 & 0.001 & 18.0 \\
\hline
\end{tabular}

Energy dispersive spectroscopy (EDS) analysis was utilized to measure the chemical compositions of the phases. Image analysis technique using the ImageJ software was used for quantification of the Nb-rich phase fraction according to ASTM E1245-03 [25]. For this analysis, fifteen SEM images were taken (with the field width of $50 \mu \mathrm{m}$ ) from each sample.

An Oxford electron backscatter diffraction (EBSD) system (Oxford Instrument, Oxfordshire, the UK), operating at accelerating voltage of $20 \mathrm{kV}$ and step size of $3 \mu \mathrm{m}$, was employed to detail the crystallographic features. Vickers microhardness (HV) measurements were performed using a Shimadzu hardness tester (HMV-2, Kyoto, Japan) by an applied load of $500 \mathrm{~g}$ and a dwell time of $15 \mathrm{~s}$. To get good statistics, fifteen hardness indentations were performed on each sample.

\subsection{Electrochemical measurements}

The electrochemical measurements were performed at room temperature using an aerated $3.5 \mathrm{wt} \% \mathrm{NaCl}$ solution, prepared with deionized water. The surface area of the samples exposed to the test solution was $1.96 \mathrm{~cm}^{2}$. Prior to each testing, the samples were rinsed with acetone, ethanol, and deionized water, dried in air at room temperature, and then transferred into the test solution. The surface of the samples was polished (with the silica suspension, $0.05 \mu \mathrm{m}$ ) in order to provide a uniform surface roughness $\left(\mathrm{R}_{\mathrm{a}}<0.1 \mu \mathrm{m}\right)$ on all the samples. The electrochemical testing was carried out using a standard three electrode system, including a graphite counter electrode, a saturated $\mathrm{Ag} / \mathrm{AgCl}$ reference electrode, and samples as working electrode. The experiments were performed on all the three samples (interior, middle, and exterior) of each group (A, B, C, and D), and the averaged results together with their standard deviations were reported.
Fig. 2 SEM (backscatter electron mode) images of the powder particles of the as-received alloy 718 powder, (a) topography, and (b) cross-section of the powder particles
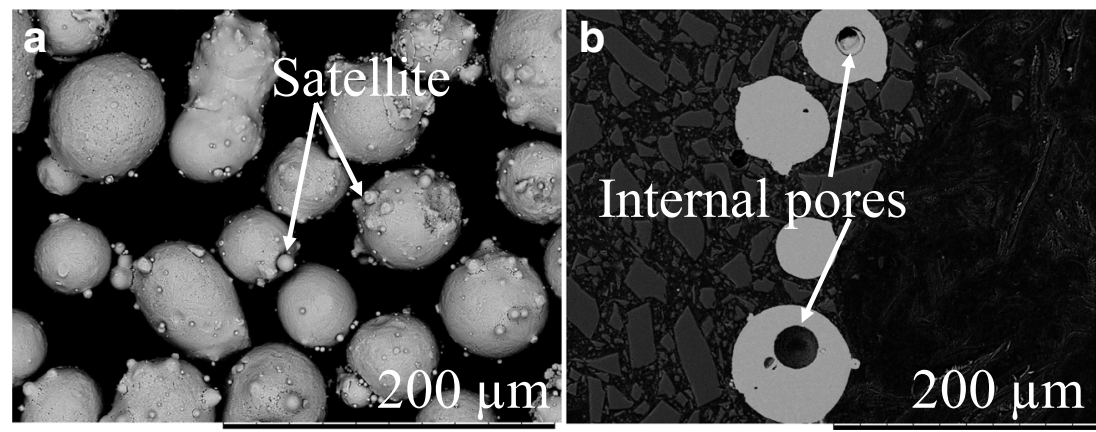
Table 2 Main EB-PBF process parameters (Arcam recommended theme) used in manufacturing of the Alloy 718 samples

\begin{tabular}{lc}
\hline Parameters & Value \\
\hline Layer thickness $(\mu \mathrm{m})$ & 75 \\
Line offset $(\mathrm{mm})$ & 0.125 \\
Speed function* & 63 \\
Scan strategy & Alternating $\sim 60^{\circ}$ in each layer
\end{tabular}

*Speed function index controls the scanning speed and beam current during the process, and for each speed function value, the scanning speed and beam current are adjusted along the build direction

The test samples were firstly immersed in the test solution for up to $1800 \mathrm{~s}$ to attain a relatively stable value of open-circuit potential (OCP). Potentiodynamic polarization tests were then performed using a Gamry instrument (Reference 3000, Pennsylvania, USA). For this series of tests, the test samples were excited from -0.2 to $1.2 \mathrm{~V}_{\mathrm{Ag} / \mathrm{AgCl}}$ at a scanning rate of $0.16 \mathrm{mV} /$ s. Electrochemical parameters such as corrosion potential $\left(E_{\text {corr }}\right)$, corrosion current density $\left(i_{\text {corr }}\right)$, cathodic Tafel slope $\left(\beta_{\mathrm{c}}\right)$, and anodic Tafel slope $\left(\beta_{\mathrm{a}}\right)$ were obtained from the potentiodynamic polarization curves. Polarization resistance $\left(R_{p}\right)$ was defined as the resistance of the sample to corrosion upon the application of an external potential according to Eq. (1):

$$
R_{p}=\frac{\beta_{a} \beta_{c}}{2.303 i_{c o r r}\left(\beta_{a}+\beta_{c}\right)}
$$

Table 3 Averaged grain width of the samples built in different locations

\begin{tabular}{cl}
\hline Sample location & Grain width $(\mu \mathrm{m})$ \\
\hline Exterior & $108 \pm 17$ \\
Middle & $122 \pm 25$ \\
Interior & $145 \pm 31$ \\
\hline
\end{tabular}

\section{Results and discussion}

\subsection{Grains structure}

In all the samples built in different locations (interior, middle, and exterior), elongated columnar grain structure perpendicular to the solidified layers along the build direction can be seen in Fig. 4a-c. Formation of the columnar structure was due to the sharp thermal gradient along the build direction during solidification. The observation of columnar grains is very common in EB-PBF built Alloy 718, in agreement with various literature $[10,16,26]$. Figure $4 d-f$ shows the effect of the location on the texture/orientation of the grains by the EBSD mapping for samples \#7, 8, and 9 as the representatives of the exterior, middle, and interior samples, respectively. It is observed that for the sample located in the exterior region (\# 7), the grains were slightly narrower due to the formation of stray grains between the columnar grains, which hindered the widening of the columnar grains. The formation of stray grains

Fig. 3 (a) Top view of the EBPBF manufactured alloy 718 samples in different groups of A, $\mathrm{B}, \mathrm{C}$, and D, (b) the sample cutting direction, and (c) temperature profile obtained from the thermocouple beneath the build plate during the EB-PBF process

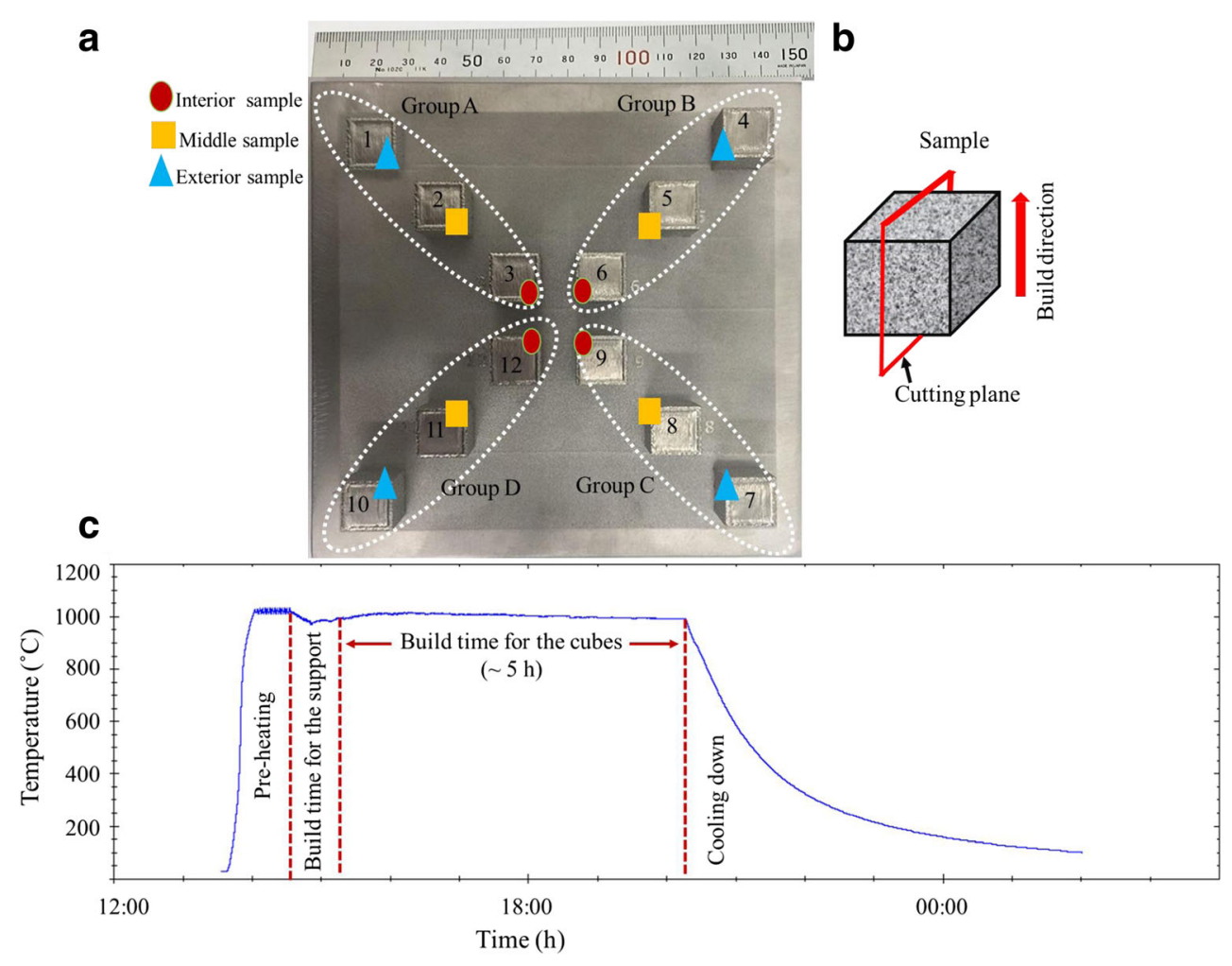


Fig. 4 SEM and EBSD mapping of the grains morphology and orientation by altering the location; (a, d) sample \#7 as the representative of the samples built in the exterior region, $(\mathbf{b}, \mathbf{e})$ sample \# 8 as the representative of the samples built in the middle region, and (c, f) sample \# 9 as the representative of the samples built in the interior region

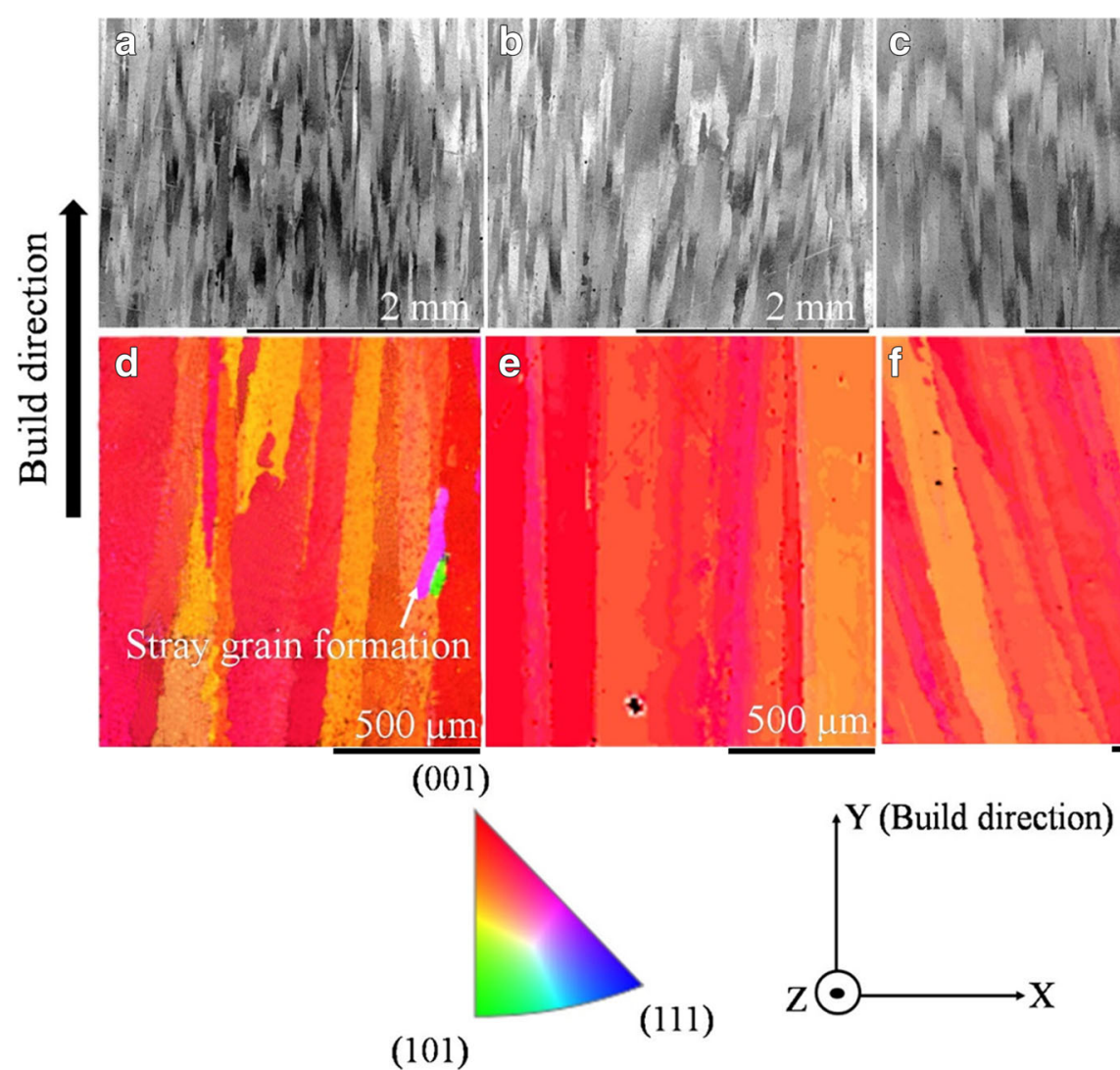

(101)

could be also due to the presence of more pores/lack-of-fusion defects which act as barriers and interrupt the columnar grain growth [27]. As shown in Fig. 4, the orientation of the grains was mainly sustained in the $<001>$ direction, and the misorientation was slightly higher in the exterior than the interior regions. From the EBSD analysis, the averaged grain width was measured and presented in Table 3. It is found that the grains were slightly wider in the sample located in the interior of the build plate compared to the samples located in the exterior regions. The source of this slightly different microstructure is most likely related to the complex thermal history/ thermal mass on the build plate during the EB-PBF process. In general, the solidified structure depends on the cooling rate, which is determined by the processing parameters for each part built by EB-PBF [27, 28].

\subsection{Variation of defects}

Figure 5 shows a general view from the distribution of the pores in the YZ plane parallel to the build direction. The main types of the pores found in the samples manufactured in different locations were (a) sphericalshaped pores (see Fig. 6a), which are assumed to be induced by the entrapped gas within the gas atomized powder particles [1] and (b) solidification or shrinkage pores in form of strings of connected round pores (see Fig. 6b).
The shrinkage pores are typically found in interdendritic regions and believed to be due to the lack of liquid to fill those regions during the last step of solidification [10, 29]. To study the influence of the sample's location on the amount of the defects, the content of the pores in the samples was measured. The results indicated that the level of pores was slightly greater in the samples located in the exterior regions of the build plate. As displayed in Fig. $6 \mathrm{~d}$, the average values of the porosity content in the exterior and interior regions of the build plate were $0.40 \pm$ 0.08 and $0.34 \pm 0.06$ area\%, respectively. The variation in the level of pores measured in different samples could be attributed to the radial reduction of heat accumulation from the center to the edge of the build plate. This leads to a faster cooling rate in the exterior region, which is surrounded by more loose powder and subsequently results in formation of more shrinkage pores. The main reason for the creation of the shrinkage pores is a lower specific volume of the solidified material than that of the melted material. Contraction of the melted material during solidification occurs, and in the case of insufficient metal to fill the last region (interdendritic area), the shrinkages pores form. At the higher cooling rate, primary dendrite arm spacing (PDAS) is finer, and there are larger interdendritic regions. Subsequently, during solidification, the volume of the liquid flow in the interdendritic regions 
Fig. 5 LOM images representing the overall surface of the samples (YZ plane) manufactured in different locations

Fig. 6 LOM and SEM images of the defects, (a-b) sample \# 1 as the representative of the samples built in the exterior region, (c) sample \# 3 as the representative of the samples built in the interior region, and (d) effect of the samples location on the level of pores
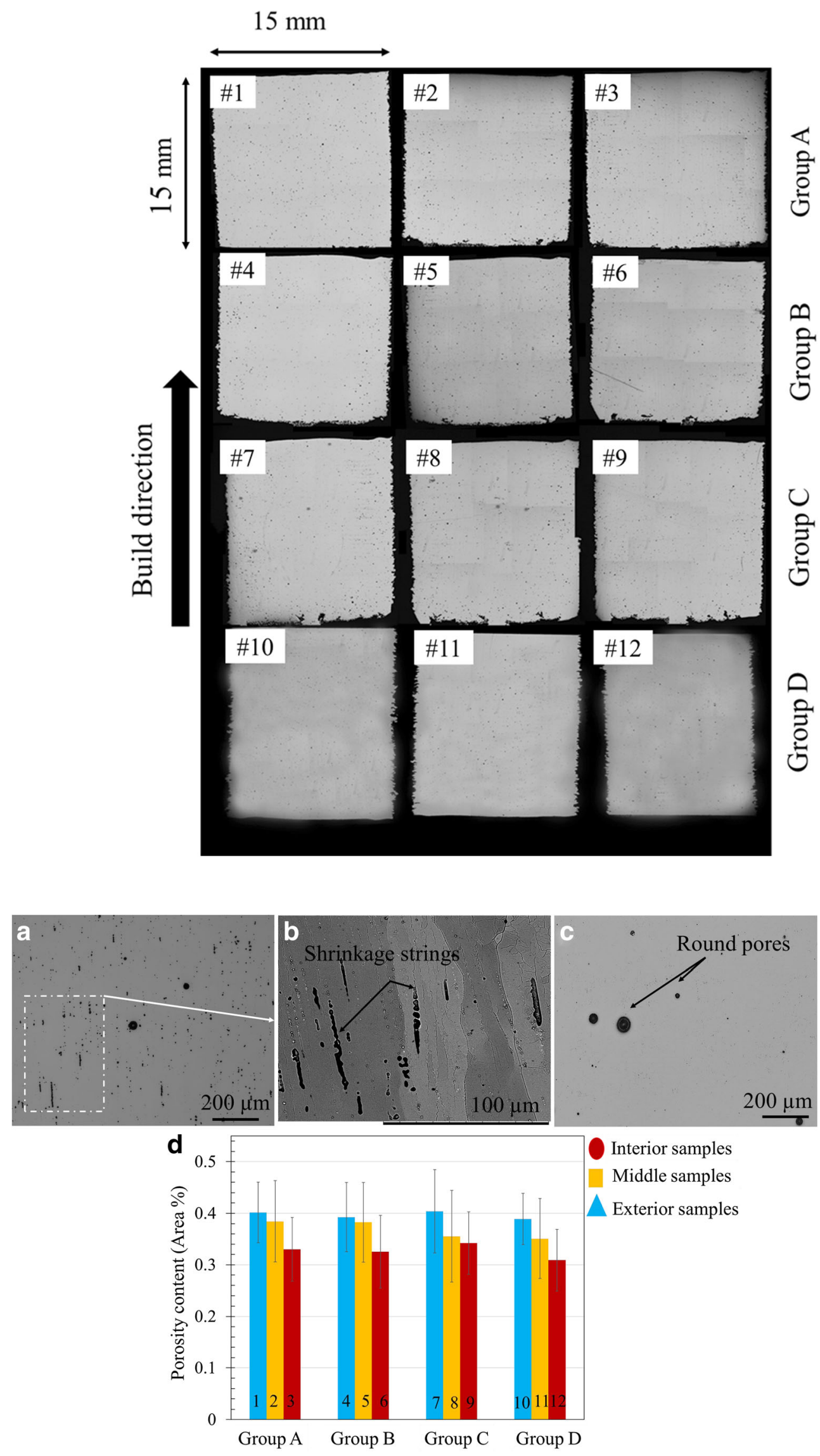
reduces due to contraction, leading to formation of a higher amount of the shrinkages pores [30].

\subsection{Variation of primary dendrite arm spacing (PDAS)}

It is well known that the solidification mode depends on solidification variables such as solidification rate $(\mathrm{V})$, cooling rate $(\bar{T})$, and thermal gradient $(\mathrm{G})$, all of which vary with time and position during solidification [30-32]. Estimation of the cooling rate can be determined by measurement of the secondary dendrite arm spacing (SDAS); however, in the absence of the secondary arms in the microstructure, the primary dendrite arm spacing (PDAS) can be considered. Figure 7 presents the cross-section of the samples \#7, 8, and 9 (as the representatives of the samples built in the exterior, middle, and interior regions, respectively) showing the primary dendrite arms. PDAS was sufficiently distinct at the top layers (Fig. 7a) to make reasonably accurate measurements along the build direction. Due to the successive thermal cycling (STC) during the EB-PBF process, the homogenization of PDAS occurs, and the dendrites were not visible in the middle or bottom of the build. Therefore, estimation of the cooling rate using PDAS at the top layers could be useful to find the changes in the thermal condition at different locations on the build plate. Figure 8 shows the averaged values of PDAS. It is observed that the samples located in the interior regions of the build plate (samples \#3, 6, 9, and 12) had high PDAS values ( $28 \%$ higher compared to the exterior samples). Based on the PDAS values (about 20 measurements), an average and standard deviation were calculated for each sample, as shown in Fig. 8. Based on a previous work [8], the cooling rate, $\dot{T}$, during the solidification process of a dendritic microstructure can be estimated using Eq. (2):

$\lambda=A \dot{\mathrm{T}}^{-n}$

where $\lambda$ is the primary dendrite arm spacing, $\mathrm{A}$ and $\mathrm{n}$ are proportionality coefficients related to materials, which can be taken to be $122.6 \mu \mathrm{m}$ and 0.342 (dimensionless) for Alloy 718 , and $\dot{T}$ is cooling rate [33]. The estimated cooling rates were approximately 1800 and $4500{ }^{\circ} \mathrm{C} / \mathrm{s}$ in the interior and exterior regions, respectively.

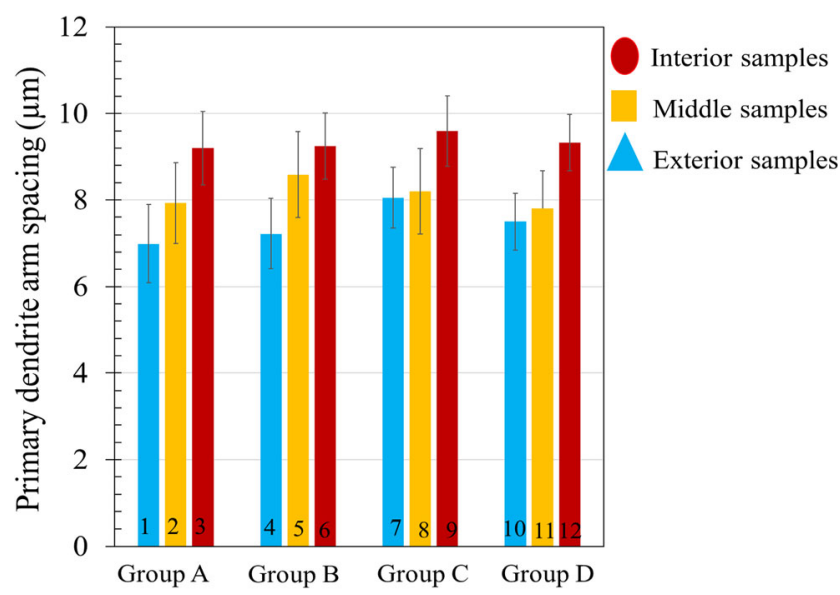

Fig. 8 Effect of the samples location on the primary dendrite arm spacing (PDAS)

\subsection{Segregation of $\mathrm{Nb}$ and variation of $\mathrm{Nb}$-rich phases}

Segregation of $\mathrm{Nb}$ occurs in EB-PBF built Alloy 718 and the commonly reported $\mathrm{Nb}$-rich phases in this material are Laves phase and $\mathrm{Nb}$-rich carbides [8, 29]. Moreover, the presence and amount of these phases are highly dependent on the thermal history of the samples. Probably, the Nb-rich phases with an irregular-script morphology observed at the interdendritic regions in the uppermost top layers were the Laves phase, see Fig. 7d. However, the $\mathrm{Nb}$-rich carbides with a round/cubic morphology were observed throughout the samples. The composition of the $\mathrm{Nb}$-rich carbides was measured by the EDS analysis, which is reported in Fig. 9. In fact, as the solidification proceeds, elements like $\mathrm{Nb}$ are depleted from the matrix, diffused to the liquid, and subsequently form phases such as $\mathrm{NbC}$ in the interdendritic regions. The segregation of $\mathrm{Nb}$ from the interdendritic regions is in agreement with other literature $[1,8,26]$. The degree of the segregation in Alloy 718 is influenced by the solidification conditions under different process conditions $[34,35]$. Figure $9 b$ shows that the content of the $\mathrm{NbC}$ particles increased upon the increase of the distance from the exterior towards the interior region of the build plate. It is pertinent to mention that all the samples were built under a fixed applied energy input. The increased amount of $\mathrm{NbC}$ can be due to the lower cooling rate (or higher heat accumulation/thermal mass) at the interior regions as
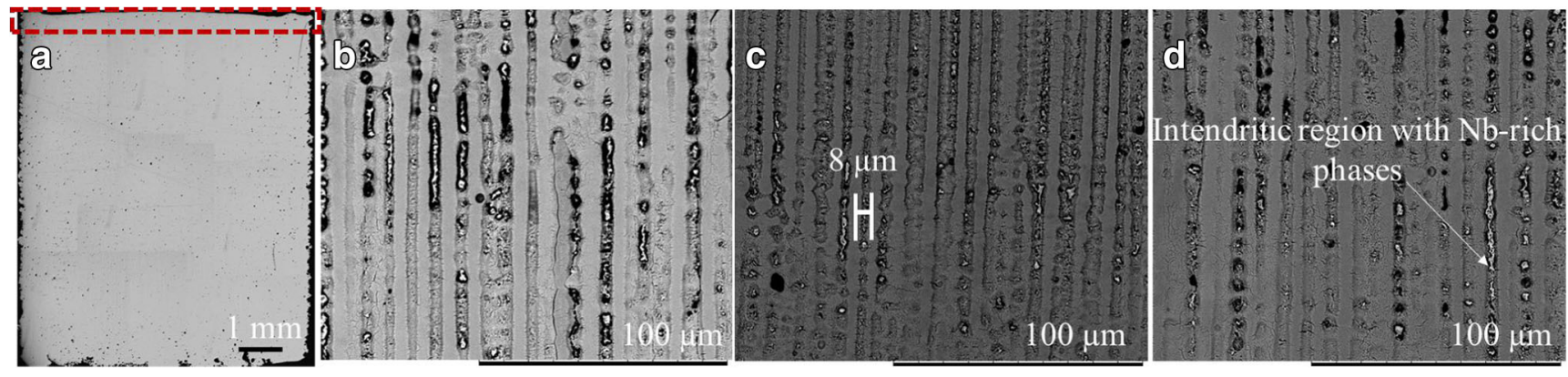

Fig. 7 (a) LOM image of the sample \# 9, as well as b, c, and d) SEM images of the primary dendrite arms in the samples \# 7, 8, and 9, respectively 
Fig. 9 a) SEM (backscattered electron mode) image of the microstructure showing the $\mathrm{NbC}$ particles as well as the tabulated EDS analysis results and (b) effect of the sample location on the $\mathrm{Nb}$-rich phase fraction a

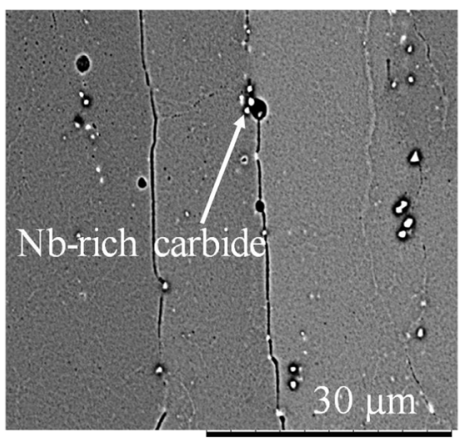

b

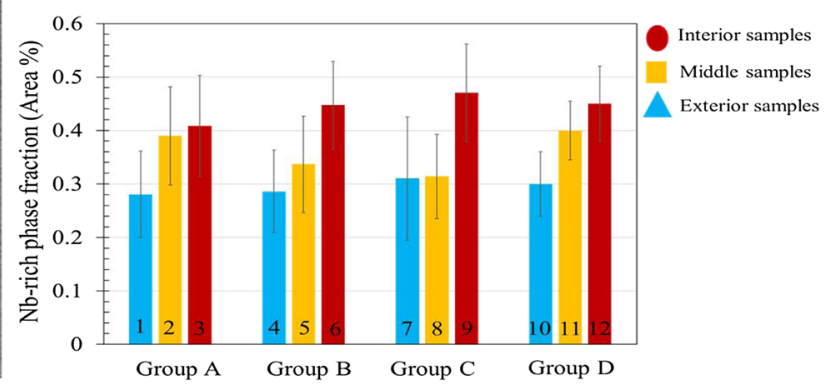

\begin{tabular}{cccccc}
\hline Elements & $\mathrm{Ni}$ & $\mathrm{Nb}$ & $\mathrm{Fe}$ & $\mathrm{Cr}$ & $\mathrm{Ti}$ \\
\hline$\gamma$ & 54.03 & 4.11 & 17.55 & 18.65 & 1.5 \\
\hline $\mathrm{MC}$ & 4.99 & 38.98 & 3.01 & 4.21 & 6.88 \\
\hline
\end{tabular}

found in the previous section (variations of PDAS). The average value of the $\mathrm{NbC}$ area fraction was around $0.28-0.55$ area\%; see Fig. 9. The large deviation in the results was sourced from the nonuniform distribution of the $\mathrm{Nb}$-rich phases in different regions. Previous studies have proven that a high cooling rate is beneficial for suppressing the segregation of $\mathrm{Nb}$ in Alloy 718 $[36,37]$.

\subsection{Variation of microhardness}

Since Alloy 718 is a precipitation-hardening alloy, appreciable changes in hardness is expected to be due to precipitation of the $\gamma^{\prime \prime}$ phase $[38,39]$. The different locations on the build plate contained various amount of heat accumulation resulting in different cooling rates and subsequently variations in the microstructure. As more heat was accumulated in the center of the build plate and cooling rates decreased, the PDAS increased simultaneously with precipitation of more $\mathrm{NbC}$ particles. However, it is reported that the changes in hardness due to slight changes of PDAS is negligible when compared to the effects of precipitates (precipitation hardening mechanism) in Alloy 718 [40]. The microhardness measurements in general did not reveal any pattern or variation with the location of the EB-PBF samples (see Fig. 10). The average value was in the range of $380-410 \mathrm{HV}_{0.5}$. This value was comparable to the values reported in the literature $[1,8,10,41]$.

\subsection{Electrochemical investigations}

\subsubsection{Open-circuit potential}

The open-circuit potentials (OCP) versus exposure time of the samples manufactured in different locations (exterior, middle, and interior) in a $3.5 \mathrm{wt} \% \mathrm{NaCl}$ for a period of $30 \mathrm{~min}$ are shown in Fig. 11. Since the four samples manufactured in each location showed similar trend, only the results of the samples \#4, 5, and 6 (exterior, middle, and interior regions, respectively) as the representatives of the other samples are shown in Fig. 11. The time profiles of OCP obtained for the three samples of \#4, 5, and 6 were quite similar. In the exterior (\#4) and middle (\#5) samples, initially OCP changed quickly towards more positive potentials during the exposure, indicating a spontaneous passivation of Alloy 718 due to the formation of a protective oxide (passive) film in the $3.5 \mathrm{wt} \% \mathrm{NaCl}$ solution [42]. The interior sample (\#6) also illustrated formation of the passive layer as the OCP of the sample reached a steady state after about $10 \mathrm{~min}$. The recorded OCP of the sample \#6 was higher than OCP of the other two samples throughout the tests. In general, the samples in the solution were gradually passivated until the OCP finally reached to relatively constant values. The noble shift of the OCP values indicated the self-passivation when the corrosion process is dominated by the passivation effect. The self-passivation of nickelbase alloys in chloride solutions has already been reported by another study [43]. It was suggested that the prevailing effect of water (which contains $\mathrm{H}_{3} \mathrm{O}^{+}$) on the alloy surface as compared with the effect of aggressive $\mathrm{Cl}^{-}$ions resulted in the ennoblement of OCP of Alloy 718 in a NaCl-laden solution [44]. From the presented OCP curves in Fig. 11, it is obvious that the interior sample (\#6) exhibited more positive values $(-0.02 \pm 0.008 \mathrm{~V}$ vs.

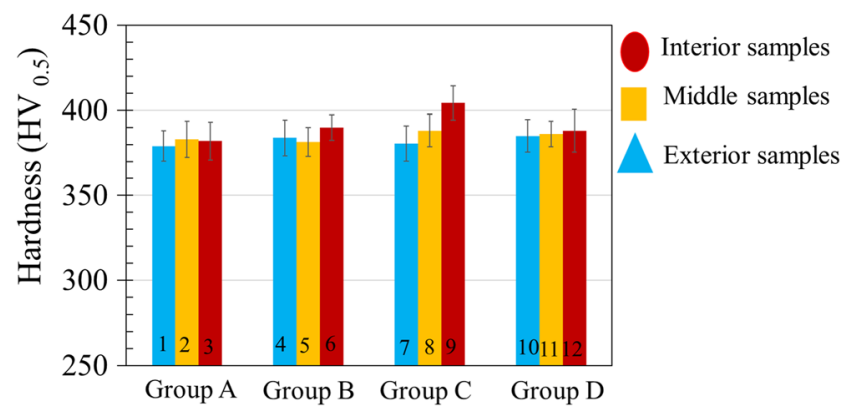

Fig. 10 Effect of the sample location on the microshardness 


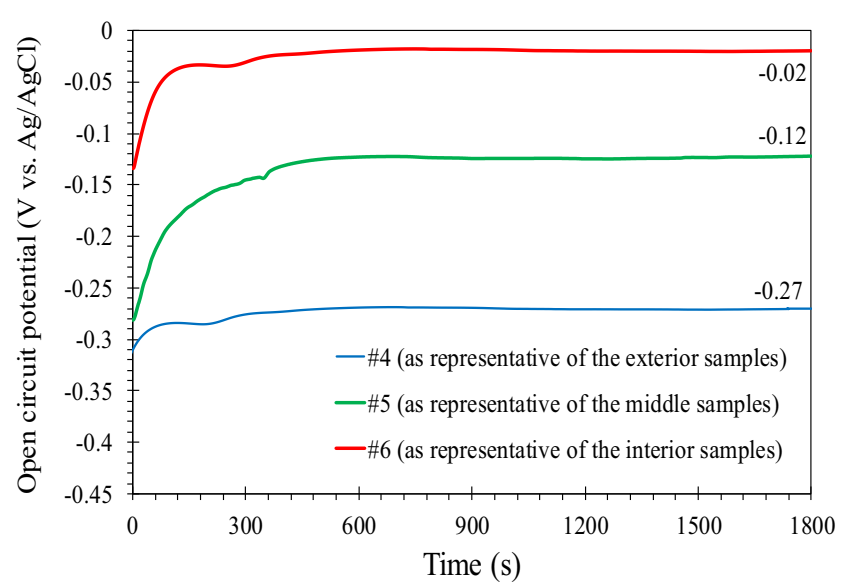

Fig. 11 Open-circuit potential (OCP) curves measured in a $3.5 \mathrm{wt} \% \mathrm{NaCl}$ solution at room temperature for the samples \# 4, 5, and 6 as the representatives for the exterior, middle, and interior samples, respectively

$\mathrm{Ag} / \mathrm{AgCl})$ compared to the other two samples $(-0.12 \pm 0.03$ and $-0.27 \pm 0.09 \mathrm{~V}$ vs. $\mathrm{Ag} / \mathrm{AgCl}$ in \#5 and \#4, respectively). The standard deviations represent the variation of the results in the four samples. The more positive OCP value might be attributed to the microstructure of the sample \#6 with lower level of pores (see Fig. 6) or the higher grain width (Table 3). The more positive OCP indicates the slower inward diffusion of $\mathrm{Cl}^{-}$towards the material, which facilitates formation of the passive (or protective) film. The OCP results that the interior sample was more corrosion resistant than the exterior sample.

\subsubsection{Potentiodynamic polarization}

Figure 12 illustrates the potentiodynamic polarization curves recorded for the samples manufactured in different locations (exterior, middle, and interior) in a $3.5 \mathrm{wt} \% \mathrm{NaCl}$ solution at room temperature. The electrochemical parameters such as corrosion potential $\left(E_{\text {corr }}\right)$, corrosion current density $\left(i_{\text {corr }}\right)$, cathodic Tafel slope $\left(\beta_{\mathrm{c}}\right)$, anodic Tafel slope $\left(\beta_{\mathrm{a}}\right)$, and polarization resistance $\left(R_{p}\right)$ obtained from the potentiodynamic polarization curves and Eq. (1) are given in Table 4. Figure 12 shows that the cathodic branches of the polarization curves displayed a typical Tafel behavior instead of a limiting diffusion current. Therefore, the cathodic process is controlled by activation polarization rather than concentration polarization in all the three samples [22]. Moreover, the well-defined cathodic Tafel regions existed over one decade of current density, which satisfies another requirement for an accurate extrapolation [19]. The anodic branches of the polarization curves also displayed a well-defined experimental Tafel region similar to the cathodic branches. This leads to obtain an accurate calculation of the anodic Tafel slopes by Tafel extrapolation. $\beta_{\mathrm{a}}, \beta_{\mathrm{c}}$ and $i_{\text {corr }}$ values were calculated and reported in Table 4 .

The results of the potentiodynamic polarization showed a significant increase of $R_{p}$ (an indicator of the corrosion resistance) from the exterior $\left(2.1 \pm 0.3 \mathrm{k} \Omega . \mathrm{cm}^{2}\right)$ to interior $(39.2 \pm$ $4.1 \mathrm{k} \Omega . \mathrm{cm}^{2}$ ) regions confirming higher corrosion resistance of the latter sample. The corrosion potential $\left(E_{\text {corr }}\right)$ shifted towards less negative values from $-0.18 \pm 0.02 \mathrm{~V}$ in the exterior region to $-0.02 \pm 0.01 \mathrm{~V}$ in the interior region. In addition, the corrosion current density $\left(i_{\text {corr }}\right)$ of the interior sample was lower $\left(8.3 \pm 2.3 \mathrm{nA} / \mathrm{cm}^{2}\right)$ compared to the exterior sample $\left(71.6 \pm 5.1 \mathrm{nA} / \mathrm{cm}^{2}\right)$. The anodic branches of the samples \# 5 and 6 were similar in the beginning, whereas a semi-passive region (a region from 0.2 to $0.7 \mathrm{~V}$ where an increase in the applied potential does not affect the current) was identified in the latter sample. The sample \# 4 and 5 only showed an increase in the anodic current with an increase in the applied potential without any clear sign for the passivity. This indicated that the metal dissolution behavior of the samples \#4 and 5 in the $3.5 \mathrm{wt} \%$ solution was active corrosion. This might be ascribed to the presence of a high $\mathrm{Cl}^{-}$concentration, leading more easily to the breakdown of the passive film [45]. The
Fig. 12 Potentiodynamic polarization curves measured in the $3.5 \mathrm{wt} \% \mathrm{NaCl}$ solution at room temperature for the samples $\# 4,5$, and 6 as the representatives for the exterior, middle, and interior samples, respectively

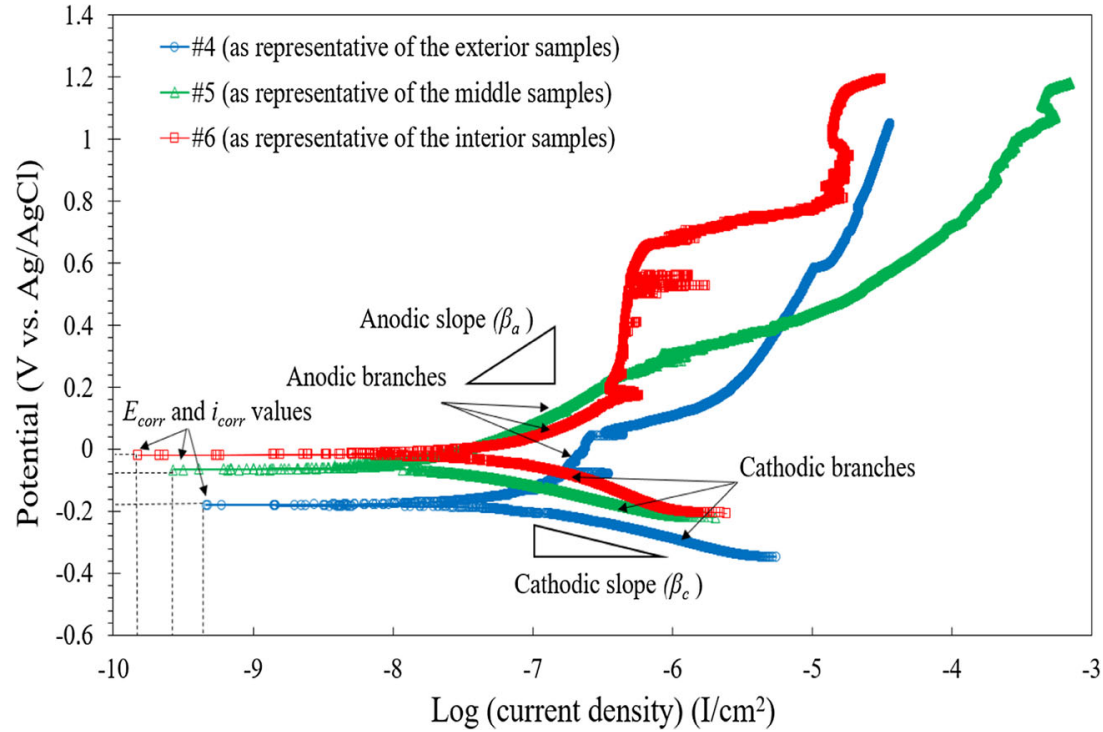


Table 4 Calculated potentiodynamic polarization results for the interior, middle, and exterior samples in the $3.5 \mathrm{wt} \% \mathrm{NaCl}$ solution at room temperature

\begin{tabular}{llcllr}
\hline Samples & $E_{\text {corr }}(\mathrm{V}$ vs. $\mathrm{Ag} / \mathrm{AgCl})$ & $i_{\text {corr }}\left(\mathrm{nA} / \mathrm{cm}^{2}\right)$ & $\beta_{a}(\mathrm{~V} /$ decade $)$ & $\beta_{c}(\mathrm{~V} /$ decade $)$ & $R_{p}\left(\mathrm{k} \Omega . \mathrm{cm}^{2}\right)$ \\
\hline Exterior & $-0.18 \pm 0.02$ & $71.6 \pm 5.1$ & $0.21 \pm 0.04$ & $0.11 \pm 0.02$ & $2.1 \pm 0.3$ \\
Middle & $-0.06 \pm 0.02$ & $29.7 \pm 3.7$ & $0.18 \pm 0.02$ & $0.08 \pm 0.01$ & $8.7 \pm 1.8$ \\
Interior & $-0.02 \pm 0.01$ & $8.3 \pm 2.3$ & $0.09 \pm 0.01$ & $0.05 \pm 0.01$ & $39.2 \pm 4.1$ \\
\hline
\end{tabular}

passive behavior in the sample \#6 verified that the sample with higher grain width and less defects was able to better sustain the corrosive environment. The larger grain width and less pores in the interior sample led to a reduction in the inward $\mathrm{Cl}^{-}$diffusion from the solution towards the bulk material, which supported formation of a more protective film on the sample's surface. Compared with the $\mathrm{E}_{\text {corr }}$ and $i_{\text {corr }}$ values of conventionally manufactured Alloy 718 reported in other studies in a similar corrosive environment [19, 46, 47], the enhanced corrosion performance of the EB-PBF built Alloy 718 can be inferred. Despite some differences in the corrosion behavior of the samples built in different locations, the present results confirmed that the EB-PBF built Alloy 718 parts can be successfully implemented in room temperature applications where low temperature corrosion is concerned.

\section{Conclusions}

The EB-PBF technique was used to build different groups of samples from Alloy 718 powder and to investigate the effect of part location on the microstructural characteristics including defects, grain structure, segregation, Vickers microhardness, and corrosion performance. The microstructural analysis disclosed a number of findings summarized as follows:

- The columnar grains parallel to the build direction had strong texture in the $<001>$ direction and was observed in all the samples manufactured in different locations. There were slightly more stray grains formed in the samples located in the exterior region.

- The amount of porosity was slightly more $(\sim 20 \%)$ in the exterior regions than the interior regions. The defects were mainly spherical pores and solidification shrinkage pores in which the latter were mainly found in the exterior region.

- Slightly less (30-35\%) Nb-rich phases was found in the exterior region.

- The primary dendrite arm spacing (PDAS) was measured and found to be coarser $(\sim 20-30 \%)$ in the samples located in the interior region.

- Microhardness did not show any clear trend in samples manufactured in different locations.

- Electrochemical tests showed that the location had a great influence on the corrosion behavior indicated by a significant increase in the polarization resistance $\left(R_{\mathrm{p}}\right)$ from the exterior $\left(2.1 \pm 0.3 \mathrm{k} \Omega . \mathrm{cm}^{2}\right)$ to interior regions $\left(39.2 \pm 4.1 \mathrm{k} \Omega . \mathrm{cm}^{2}\right)$.
Acknowledgments Open access funding provided by University West. The authors would like to thank Mr. Jonas Olsson for sharing his knowledge in running the EB-PBF machine. Funding from the "European Regional Development Fund," the "Simulation and Control of Material affecting Processes" (SiCoMap), and the "Sustainable Manufacturing Through Next-Generation Additive Process" (SUMAN-Next) projects with funding from the KK foundation are highly acknowledged.

Open Access This article is licensed under a Creative Commons Attribution 4.0 International License, which permits use, sharing, adaptation, distribution and reproduction in any medium or format, as long as you give appropriate credit to the original author(s) and the source, provide a link to the Creative Commons licence, and indicate if changes were made. The images or other third party material in this article are included in the article's Creative Commons licence, unless indicated otherwise in a credit line to the material. If material is not included in the article's Creative Commons licence and your intended use is not permitted by statutory regulation or exceeds the permitted use, you will need to obtain permission directly from the copyright holder. To view a copy of this licence, visit http://creativecommons.org/licenses/by/4.0/.

\section{References}

1. W. J. Sames V., “Additive manufacturing of Inconel 718 using electron beam melting: processing, post-processing, \& mechanical properties," PhD Thesis, 2015

2. Karimi P, Raza T, Andersson J, Svensson L-E (Feb. 2018) Influence of laser exposure time and point distance on 75- $\mu$ m-thick layer of selective laser melted alloy 718. Int J Adv Manuf Technol 94(5): 2199-2207

3. Frazier WE (Jun. 2014) Metal additive manufacturing: a review. J Mater Eng Perform 23(6):1917-1928

4. Mellor S, Hao L, Zhang D (Mar. 2014) Additive manufacturing: a framework for implementation. Int J Prod Econ 149:194-201

5. Gao W et al (Dec. 2015) The status, challenges, and future of additive manufacturing in engineering. Comput Aided Des 69:65-89

6. Algardh JK et al (Oct. 2016) Thickness dependency of mechanical properties for thin-walled titanium parts manufactured by Electron beam melting (EBM). Addit Manuf 12:45-50

7. E. Sadeghimeresht et al., "Isothermal oxidation behavior of EBMadditive manufactured alloy 718," in Proceedings of the 9th International Symposium on Superalloy 718 \& Derivatives: Energy, Aerospace, and Industrial Applications, 2018, pp. 219-240

8. Karimi P, Sadeghi E, Åkerfeldt P, Ålgårdh J, Andersson J (Dec. 2018) Influence of successive thermal cycling on microstructure evolution of EBM-manufactured alloy 718 in track-by-track and layer-by-layer design. Mater Des 160:427-441

9. Sames WJ, Unocic KA, Dehoff RR, Lolla T, Babu SS (Sep. 2014) Thermal effects on microstructural heterogeneity of Inconel 718 materials fabricated by electron beam melting. J Mater Res 29: 1920-1930

10. Karimi P, Sadeghi E, Deng D, Gruber H, Andersson J, Nylen P (2018) Influence of build layout and orientation on microstructural 
characteristics of electron beam melted alloy 718. Int J Adv Manuf Technol 99(S1):2903-2913

11. Hrabe NW, Quinn TP, Kircher R (Jun. 2013) Effects of Processing on Microstructure and Mechanical Properties of Ti-6Al-4V Fabricated using Electron Beam Melting (EBM), Part 2: Energy Input, Orientation, and Location. Mater. Sci. Eng. -Struct. Mater. Prop. Microstruct. Process 573

12. Alsalla HH, Smith C, Hao L (Nov. 2017) Effect of build orientation on the surface quality, microstructure and mechanical properties of selective laser melting 316L stainless steel. Rapid Prototyp J 24(1): 9-17

13. Scharowsky T, Juechter V, Singer RF, Körner C (Nov. 2015) Influence of the scanning strategy on the microstructure and mechanical properties in selective Electron beam melting of Ti-6Al4V. Adv Eng Mater 17(11):1573-1578

14. Galarraga H, Lados DA, Dehoff RR, Kirka MM, Nandwana P (Apr. 2016) Effects of the microstructure and porosity on properties of Ti-6Al-4V ELI alloy fabricated by electron beam melting (EBM). Addit. Manuf. 10:47-57

15. Hrabe N, Quinn T (Jun. 2013) Effects of processing on microstructure and mechanical properties of a titanium alloy (Ti-6Al-4V) fabricated using electron beam melting (EBM), part 1: distance from build plate and part size. Mater Sci Eng A 573:264-270

16. Sames W (2015) Additive manufacturing of Inconel 718 using electron beam melting: processing, post-processing, \& mechanical properties. Doctoral thesis

17. J. A. E. Andersson, "Weldability of precipitation hardening Superalloys - influence of microstructure," 2011

18. "Influence of build layout and orientation on microstructural characteristics of electron beam melted Alloy 718," springerprofessional.de. [Online]. Available: https://www. springerprofessional.de/influence-of-build-layout-and-orientationon-microstructural-cha/16131392. [Accessed: 26-Feb-2019]

19. Chen T, John H, Xu J, Lu Q, Hawk J, Liu X (Dec. 2013) Influence of surface modifications on pitting corrosion behavior of nickelbase alloy 718. Part 1: effect of machine hammer peening. Corros Sci 77:230-245

20. Sadeghi E, Karimi P, Momeni S, Seifi M, Eklund A, Andersson J (Apr. 2019) Influence of thermal post treatments on microstructure and oxidation behavior of EB-PBF manufactured alloy 718. Mater Charact 150:236-251

21. Sanviemvongsak T, Monceau D, Macquaire B (Aug. 2018) High temperature oxidation of IN 718 manufactured by laser beam melting and electron beam melting: effect of surface topography. Corros Sci 141:127-145

22. Jones DA (1995) Principles and Prevention of Corrosion, 2 edition. Pearson, Upper Saddle River, NJ

23. Ralston KD, Birbilis N (Jul. 2010) Effect of grain size on corrosion: a review. CORROSION 66(7):075005-075005-13

24. "ASTM E562-08, standard test method for determining volume fraction by systematic manual point count, ASTM International, West Conshohocken, PA, 2008, www.astm.org.

25. "Determining the inclusion or second-phase constituent content of metals by automatic image analysis," Scribd. [Online]. Available: https://www.scribd.com/document/370262651/ASTM-E12452003-R-2008-929519503392. [Accessed: 05-Jul-2019]

26. Kirka MM, Unocic KA, Raghavan N, Medina F, Dehoff RR, Babu SS (Mar. 2016) Microstructure development in electron beammelted Inconel 718 and associated tensile properties. JOM 68(3): 1012-1020

27. P. Karimi, "Electron beam melting of Alloy 718: influence of process parameters on the microstructure," Licentiate Thesis, University West, Trollhattan, Sweden, 2018

28. Karimi P, Sadeghi E, Ålgårdh J, Andersson J (2019) EBMmanufactured single tracks of Alloy 718: influence of energy input and focus offset on geometrical and microstructural characteristics. Mater Charact 148:88-99

29. Strondl A, Fischer R, Frommeyer G, Schneider A (May 2008) Investigations of MX and $\gamma^{\prime} / \gamma^{\prime \prime}$ precipitates in the nickel-based superalloy 718 produced by electron beam melting. Mater Sci Eng A 480(1):138-147

30. Carlson KD, Beckermann C (Jan. 2009) Prediction of shrinkage pore volume fraction using a dimensionless Niyama criterion. Metall Mater Trans A 40(1):163-175

31. Helmer HE, Körner C, Singer RF (Sep. 2014) Additive manufacturing of nickel-based superalloy Inconel 718 by selective electron beam melting: processing window and microstructure. J Mater Res 29(17):1987-1996

32. Helmer H, Bauereiß A, Singer RF, Körner C (2016) Grain structure evolution in Inconel 718 during selective electron beam melting. Mater Sci Eng Struct Mater Prop Microstruct Process 668:180-187

33. Superalloys supercomposites superceramics. Elsevier, 1989

34. Liu WC, Yao M, Chen ZL, Wang SG (Jun. 1999) Niobium segregation in Inconel 718. J Mater Sci 34(11):2583-2586

35. Pan X, Yu H, Tu G, Sun W, Hu Z (Nov. 2011) Segregation and diffusion behavior of niobium in a highly alloyed nickel-base superalloy. Trans Nonferrous Met Soc China 21(11):2402-2407

36. Kou S (2002) Welding metallurgy, 2nd edn

37. Long Y, Nie P, Li Z, Huang J, Li X, Xu X (Feb. 2016) Segregation of niobium in laser cladding Inconel 718 superalloy. Trans. Nonferrous Met. Soc. China 26(2):431-436

38. Tucho WM, Cuvillier P, Sjolyst-Kverneland A, Hansen V (Mar. 2017) Microstructure and hardness studies of Inconel 718 manufactured by selective laser melting before and after solution heat treatment. Mater Sci Eng A 689:220-232

39. Azadian S (2004) Aspects of precipitation in alloy Inconel 718. Luleå Tekniska Universitet, Doctoral Thesis

40. Zuback JS, DebRoy T (Oct. 2018) The hardness of additively manufactured alloys. Mater. Basel Switz, 11(11)

41. Goel S, Olsson J, Ahlfors M, Klement U, Joshi S (2018) The effect of location and post-treatment on the microstructure of EBM-built alloy 718. In: Ott E, Liu X, Andersson J, Bi Z, Bockenstedt K, Dempster I, Groh J, Heck K, Jablonski P, Kaplan M, Nagahama D, Sudbrack C (eds) Proceedings of the 9th international symposium on superalloy $718 \&$ derivatives: energy, aerospace, and industrial applications. Springer International Publishing, Cham, pp 115-129

42. Rybalka KV, Beketaeva LA, Davydov AD (Jan. 2012) Effect of self-passivation on the electrochemical and corrosion behaviour of alloy C-22 in NaCl solutions. Corros Sci 54:161-166

43. Macdonald DD (Aug. 2011) Theoretical investigation of the evolution of the passive state on alloy 22 in acidified, saturated brine under open circuit conditions. Electrochim Acta 56(21):7411-7420

44. Amin MA, El-Bagoury N, Saracoglu M, Ramadan M (2014) Electrochemical and corrosion behavior of cast re-containing Inconel 718 alloys in sulphuric acid solutions and the effect of cl. Int J Electrochem Sci 9:5352-5374

45. Chen T, Nutter J, Hawk J, Liu X (Dec. 2014) Corrosion fatigue crack growth behavior of oil-grade nickel-base alloy 718. Part 1: effect of corrosive environment. Corros Sci 89:146-153

46. Bansal A, Sharma AK, Kumar P (May 2017) Galvanic corrosion behavior of microwave welded and post-weld heat-treated Inconel718 joints. J Mater Eng Perform 26(5):2322-2330

47. Wang J, Xu J, Zhang X, Ren X, Song X, Chen X (2018) An Investigation of Surface Corrosion Behavior of Inconel 718 after Robotic Belt Grinding. Materials 11(12):2440

Publisher's note Springer Nature remains neutral with regard to jurisdictional claims in published maps and institutional affiliations. 